\title{
Application of rib surface positioning ruler combined with volumetric CT measurement technique in endoscopic minimally invasive thoracic wall fixation surgery
}

\author{
HONGGANG XIA ${ }^{1 *}$, ZHONGYI SUN $^{1 *}$, JUPING WANG $^{2}$, AIXIAN TIAN ${ }^{1}$, JING LI $^{3}$, \\ XUAN LI ${ }^{1}$, SHAN ZHU ${ }^{1}$, JUN MIAO ${ }^{1}$ and DONGBIN WANG ${ }^{1}$ \\ ${ }^{1}$ Department of Cardiothoracic Surgery, Tianjin Hospital Affiliated to Tianjin University, Tianjin 300000; \\ ${ }^{2}$ Department of Cardiology, Beichen District Hospital of Traditional Chinese Medicine, Tianjin 300400; \\ ${ }^{3}$ Department of Basic Nursing, Tianjin Medical College, Tianjin 300222, P.R. China
}

Received September 25, 2019; Accepted March 4, 2020

DOI: $10.3892 /$ etm.2020.8862

\begin{abstract}
Application value of rib surface positioning ruler combined with volumetric $\mathrm{CT}$ measurement in selection of the incision for minimally invasive internal fixation of rib fracture was investigated. A total of 80 patients who received internal fixation of rib fractures in Tianjin Hospital Affiliated to Tianjin University (Tianjin, China) from May 2018 to April 2019 were selected. Patients were treated with the rib surface positioning ruler combined with volumetric $\mathrm{CT}$ measurement method $(n=42)$ or traditional positioning method $(n=38)$. The following parameters were compared between the two groups: Preset incision accuracy, operation incision length, operation time, intraoperative bleeding volume, postoperative wound drainage volume and postoperative pain score. Compared with the traditional positioning method, rib surface positioning ruler combined with volumetric CT measurement method can improve preset incision accuracy, reduce operation time, incision length, intraoperative bleeding volume, postoperative wound drainage volume, and postoperative pain score, with statistically significant differences $(\mathrm{P}<0.05)$. In conclusion, the application of rib surface positioning ruler combined with volumetric CT measurement technique has obvious effect on the selection of incision for internal fixation of rib fracture, and is an effective method worth promoting.
\end{abstract}

Correspondence to: Dr Jun Miao or Dr Dongbin Wang, Department of Cardiothoracic Surgery, Tianjin Hospital Affiliated to Tianjin University, 406 Jiefang South Road, Hexi, Tianjin 300000, P.R. China

E-mail: mj6688@163.com

E-mail: 13516263681@163.com

*Contributed equally

Key words: minimally invasive chest wall fixation, rib surface positioning ruler, volumetric CT measurement, positioning method

\section{Introduction}

Chest trauma is the second leading cause of trauma-related deaths, accounting for $20-25 \%$ of all trauma-related deaths (1). Multiple rib fractures, especially in patients with flail chest, are often accompanied by severe pain, chest wall softening, abnormal breathing and severe lung contusion. As multiple rib fractures may easily lead to respiratory failure and even threaten life, thoracic surgery is often required. The surgical treatment of patients with flail chest and $>4$ consecutive dislocated rib fractures has achieved satisfactory results (2-5). Since the ribs are flat bones in long arc shape, the surface area of the chest is large, and the operation involves multiple ribs, a large incision is required to obtain a satisfactory exposure of the surgical field. Some chest wall muscles, blood vessels and nerves are often injured during operation, resulting in increased infection rate of the incision after operation, which easily leads to dysfunction and skin numbness on the lateral chest wall. The improvement of operation incision accuracy can reduce the injury to chest wall muscles, peripheral blood vessels and nerves, save operation time, reduce postoperative pain, and accelerate the recovery of patients. Therefore, determining the incision before operation is very important. In the present study, 80 patients with rib fracture treated by internal fixation in Tianjin Hospital Affiliated to Tianjin University (Tianjin, China) from May 2018 to April 2019 were selected and divided into two groups. The patients in the two groups were treated following different methods of rib positioning before operation. The clinical value of using rib surface positioning ruler (National Patent Application, patent no. 201920 189426.4) (6) combined with volumetric CT measurement technique to determine the operative incision was investigated.

\section{Patients and methods}

Clinical information. A total of 80 patients who received internal fixation of rib fractures in Tianjin Hospital Affiliated to Tianjin University from May 2018 to April 2019 were 
selected as research subjects, including 47 males and 33 females. Patients were 25-73 years of age, with an average age of 44.5 years. There were 48 patients injured in traffic accidents, 17 patients injured after falling from high places, 9 patients injured from falls, and 6 patients with severe crush injuries. All patients had multiple rib fractures ( $\geq 4$ with dislocation of the broken ends) and pulmonary contusion after injury. Among them, 51 patients had flail chest or local chest wall deformity. The patients were divided into two groups, the experimental and the control group. In the experimental group, 42 patients were treated with rib surface positioning ruler combined with $\mathrm{CT}$ measurement method. In the control group, 38 patients were treated with traditional positioning method. There was no significant difference in clinical data between the two groups, as shown in Table I.

Indications and timing for operation. Operation for multiple rib fractures with dislocation of $\geq 4$ broken ends should be performed 2-5 days after injury. Patients with multiple injuries should receive surgical treatment after their general condition was stable, but no more than $>7$ days. Patients with severe abnormal breathing and flail chest should be treated surgically in time.

Operation incision position. The position of the operation incision should first meet the needs of surgery, and then ensure that the operation is minimally invasive. Operation incision based on traditional positioning and on the method of rib surface positioning ruler combined with volumetric CT measurement was explored. Traditional positioning group: Combined with three-dimensional (3D) CT imaging and chest wall contusion marks, transverse or longitudinal incision was made along the ribs. Method of rib surface positioning ruler: Before operation, the surface distance between the fracture plane of the ribs and the surface sign plane of the chest was measured as the longitudinal coordinate in the fusion CT image system (the distance between the anterior ribs and the sternum angle plane, the distance between the posterior ribs and the body spinous process of the cervical 7 vertebrae). The surface distance between the fracture lines of the ribs and the midline of the human body was measured as the transverse coordinate (the midline of the sternum or spinous process of the spine) (Fig. 1). The frame surface positioning ruler was used to determine the ordinate. The ' 0 ' scale corresponds to the sternal angle plane or the cervical 7 vertebral body spinous process plane, the slide slips to the longitudinal coordinate value; then, the ulna was pulled horizontally, and the sternal midline or spinal spinous process was taken as the ' 0 ' scale to locate the transverse coordinate value. The line-drawing pen was used to mark the surface position of the broken end of the fracture of the ribs (Fig. 2).

Operation method. All patients underwent transosseous thoracic tunnel-type endoscopic internal fixation of ribs (7). Pure titanium rib bone plate was used as the fixation material. The specific surgical procedure was as follows: Single cavity intubation was performed under general anesthesia. According to the location and number of ribs fractured, the patient's surgical position (such as, the hypothesis, the prone position, left and right lateral position) was designed.
Table I. Comparison of general information between the two groups of patients.

\begin{tabular}{lccc}
\hline Group & Male/female & $\begin{array}{c}\text { No. of } \\
\text { fixed } \\
\text { bones }\end{array}$ & $\begin{array}{c}\text { No. of fixed } \\
\text { plates } \\
\text { used }\end{array}$ \\
\hline Experimental group & $25 / 17$ & $4.96 \pm 1.18$ & $5.02 \pm 1.02$ \\
Control group & $22 / 16$ & $4.76 \pm 1.04$ & $5.08 \pm 1.16$ \\
t/ $\chi^{2}$ & 0.042 & 0.568 & 0.412 \\
P-value & 0.812 & 0.572 & 0.658 \\
\hline
\end{tabular}

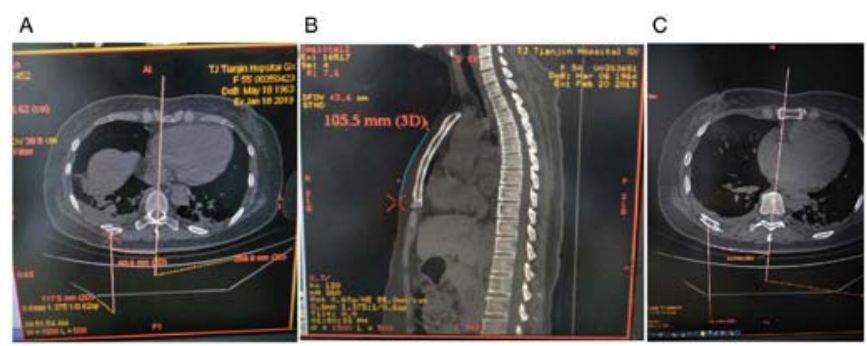

Figure 1. Volumetric CT technique measures various effective parameters on the body surface positioning of the fracture. (A) Curvilinear distance from the broken end of the posterior rib to the spinous process. (B) Curvilinear distance from the broken end of the side frame to the spinous process. (C) Curvilinear distance from the broken end of the fracture to the sternal angle.

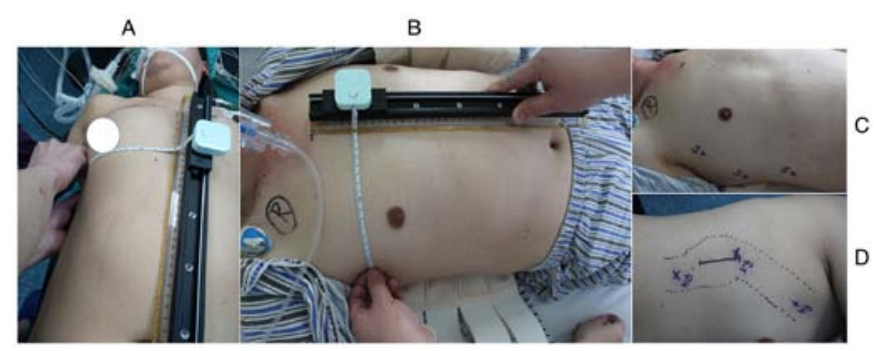

Figure 2. Body surface positioning ruler was used to mark the rib fracture on the body surface. (A) Measurement of the distance from the broken posterior rib end to the center of the sternum. (B) Measurement of the distance from the broken side fore rib end to the center of the sternum. (C) Body surface identification of the broken end of the fracture. (D) Body surface range of bony thoracic surface tunnel.

The surface position was located through the combined use of frame body positioning ruler and marked volumetric CT measurement data, and the location of incision was identified according to the surface position and the fracture position of chest wall muscles anatomical distribution. General center of the juggle multiple fractured ribs and chest wall muscle clearance (commonly used approaches: Pectoralis major approach, lower marginal mammary approach, auscultation triangle approach, vertical spinal muscle lateral approach, axillary approach) were taken into consideration. Incision could be transverse, longitudinal or oblique, fully free of subcutaneous and muscle layers. The incision should be made along the muscle gap and muscle texture to the surface of the bone thorax, avoiding breaking the muscle, cutting off part of the muscle attachment 
Table II. Accuracy of preset incision in the two groups.

\begin{tabular}{lccc}
\hline Group & Cases & $\begin{array}{c}\text { Accurate } \\
\text { prediction }\end{array}$ & $\begin{array}{c}\text { Inaccurate } \\
\text { prediction }\end{array}$ \\
\hline Experimental group & 42 & 39 & 3 \\
Control group & 38 & 30 & 8 \\
\hline
\end{tabular}

Compared with the control group, the accuracy of the preset incision was significantly increased in the experimental group $\left(\chi^{2}=4.820\right.$, $\mathrm{P}=0.027$ ).

Table III. Comparison of operation time and incision length between the two groups.

\begin{tabular}{lcc}
\hline Group & $\begin{array}{c}\text { Operation } \\
\text { time }(\mathrm{min})\end{array}$ & $\begin{array}{c}\text { Length of operation } \\
\text { incision }(\mathrm{cm})\end{array}$ \\
\hline Experimental group & $53.26 \pm 9.32$ & $6.25 \pm 1.02$ \\
Control group & $70.50 \pm 11.01$ & $10.23 \pm 1.35$ \\
P-value & 0.003 & 0.017 \\
\hline
\end{tabular}

Table IV. Comparison of intraoperative bleeding volume and postoperative wound drainage volume between the two groups.

\begin{tabular}{|c|c|c|}
\hline Group & $\begin{array}{c}\text { Bleeding } \\
\text { volume }(\mathrm{ml})\end{array}$ & $\begin{array}{l}\text { Wound drainage } \\
\text { volume }(\mathrm{ml})\end{array}$ \\
\hline Experimental group & $20.17 \pm 10.43$ & $45.72 \pm 7.21$ \\
\hline Control group & $40.58 \pm 12.15$ & $65.35 \pm 14.13$ \\
\hline P-value & 0.001 & 0.002 \\
\hline
\end{tabular}

points along the surface of the bone thorax, and using a special intrathoracic wall extension surgical instrument to support the muscle thorax in the direction perpendicular to the bone thorax, so as to separate the skeletal thorax and muscle thorax. Using this space, thoracoscopy was used to free the necessary muscle chest, forming a temporary tunnel in the chest wall. After the fracture in the distance of the tunnel was reset, a rib fixing plate was required to be buckled on both sides of the rib fracture of the anatomical reduction along the running direction of the rib, and the rib fixing plate was fixed on the broken-end surface of the fracture by using a special clamp.

Observation indices. The preset incision accuracy, incision length, operation time, intraoperative bleeding volume, postoperative wound drainage volume and postoperative pain score were recorded and compared between the two groups.

Statistical analysis. SPSS 19.0 software (IBM Corp.) was used for statistical analysis of the data. The results were expressed as the mean \pm standard deviation (SD). VAS score, intraoperative bleeding volume, postoperative wound drainage volume, operation time and incision length were analyzed by t-test, whereas Chi-square test was used for the accuracy of preset incision. $\mathrm{P}<0.05$ was considered to indicate a statistically significant difference.

\section{Results}

Postoperative pain was significantly reduced in patients who underwent transosseous thoracic tunneling internal fixation, and the difference between the two groups was statistically significant $(\mathrm{P}<0.05)$. In the experimental group, the accuracy of the preset incision was significantly increased (Table II), and the operation time, incision length (Table III), intraoperative bleeding volume, postoperative wound drainage volume (Table IV) and postoperative pain score (Table V) were significantly reduced, compared with those on the control group. The differences were statistically significant (Tables II-V).

\section{Discussion}

Multiple rib fractures often occur in chest injuries, accompanied by local pain and limited breathing. When flail chest is present, patients may exhibit abnormal breathing movements, which may lead to circulatory dysfunction, acute respiratory distress syndrome, or multiple organ failure. Therefore, fixing rib fractures in chest injuries is necessary (8-12). For multiple rib fractures, methods such as chest band compression external fixation and ventilator-assisted breathing, were used in the past to improve the condition of chest wall collapse and abnormal breathing to some extent. Currently, with the development of medical technology and the emergency of new internal fixation materials $(13,14)$, the treatment of multiple rib fractures by internal rib fixation has become an industry consensus. Internal rib fixation surgery can relieve patients' pain and reduce the related complications, speed the recovery of the patients, and improve the prognosis of patients. Due to the progress made on surgical techniques, including the clinical application of $3 \mathrm{D}$ printing and the emergence of new operation materials, especially the fracture fixation material, surgery is becoming minimally invasive, leading to the reduction of surgical complications (15-17) and requiring accurate positioning of the incision. Some studies have analyzed the problem of surgical approach, but the incision site cannot be accurately positioned yet (18).

Currently, patients with rib fractures usually receive 3D CT examination of the ribs for a clear diagnosis of the contraposition of fracture ends. In the traditional rib-positioning method, the surgeon determines the operation incision of the patient relying on his own 3D interpretation through 3D CT imaging of the ribs before surgery, which usually has some errors. Some experts have tried thoracoscopy (VATS) to locate the fractured end of rib fractures; however, this operation requires the insert of the scope tube into the chest cavity, breaking the integrity of the pleural cavity. The surgical path in order to fix the ribs is through the rib cage, rather than through the bony extrathoracic tunnel path, causing heavy damage. Clinical practice confirms that severely misplaced rib fractures are difficult to fix with ribs in the thorax. In addition, there are few options for fixing materials. Therefore, 
Table V. Comparison of VAS scores before and after operation.

\begin{tabular}{lccrr}
\hline Time & Experimental group & Control group & $\mathrm{t}$ & P-value \\
\hline Before operation & $7.32 \pm 1.05$ & $7.35 \pm 1.04$ & -1.132 & 0.173 \\
1 day after operation & $3.75 \pm 1.12$ & $4.75 \pm 1.05$ & 1.022 & 0.003 \\
3 days after operation & $3.53 \pm 1.07$ & $3.97 \pm 1.13$ & 1.017 & 0.002 \\
\hline
\end{tabular}

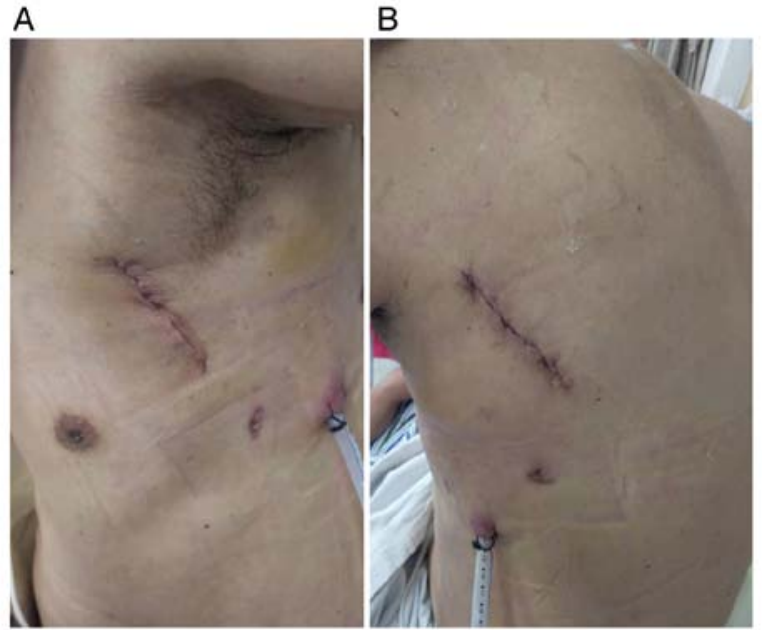

Figure 3. Minimally invasive surgical incision after application of the body surface positioning ruler. (A) Minimally invasive incision in anterior chest wall. (B) Minimally invasive incision in posterior thoracic wall.

it is difficult to promote in clinical practice. B-ultrasound positioning of rib fractures before surgery may cause severe pain. Moreover, the surgeon is important to have certain experience in B-ultrasonic operation, and it is difficult to locate a fracture with minor displacement. According to a cross-sectional study (19) on the evaluation of 61 patients with rib fractures, B-ultrasound is more sensitive than X-rays and requires less time to diagnose. Because of the anatomical characteristics of the ribs and the large surface area of the chest wall, it is very important to determine the incision of internal fixation of rib fracture. Accurately selecting the incision can make the surgery minimally invasive, reduce the injury of chest wall muscles, the damage to peripheral blood vessels and nerves, the operation time and the postoperative pain, and accelerate the recovery of patients. The application of the rib surface positioning ruler combined with the CT measurement technique can more accurately determine the surface position of the rib fracture and preset the operation incision (Figs. 3 and 4). Although the change of posture may cause some errors, compared with the traditional rib-positioning method, it still has obvious advantages, which can make the operation more smooth and lead to fewer postoperative complications.

In summary, in the surgical treatment of multiple rib fractures, the preoperative use of rib surface positioning ruler combined with volumetric CT measurement and positioning method to preset the operation incision, can reduce the length of operation incision, the operation time, the postoperative pain of patients, and the incidence of related complications,

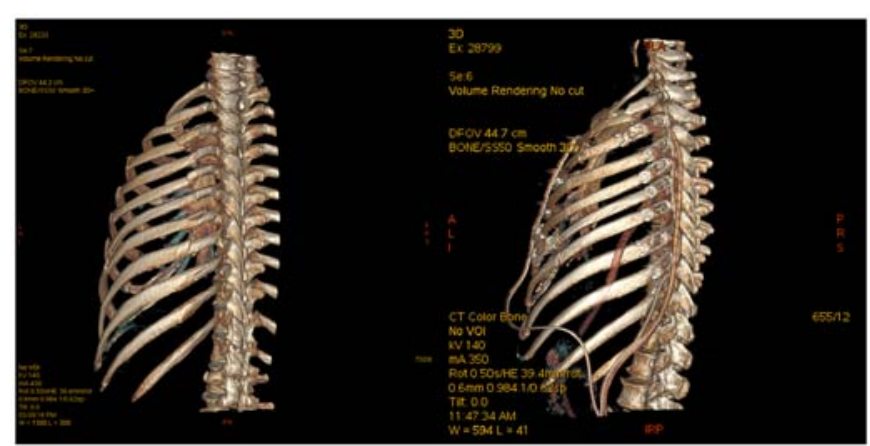

Figure 4. Comparison of the ribs before and after treatment.

suggesting that this method is worthy of wide promotion in clinical practice.

\section{Acknowledgements}

Not applicable.

\section{Funding}

No funding was received.

\section{Availability of data and materials}

The datasets used and/or analyzed during the present study are available from the corresponding author on reasonable request.

\section{Authors' contributions}

HX, ZS and JW conceived and designed the study. AT and JL acquired the data. XL was responsible for the determination of the operation incision site. SZ, JM and DW were responsible for the operation. All authors read and approved the final version of the manuscript.

\section{Ethics approval and consent to participate}

The study was approved by the Ethics Committee of Tianjin Hospital Affiliated to Tianjin University (Tianjin, China). Signed written informed consents were obtained from the patients and/or guardians.

\section{Patient consent for publication}

Patients agreed to their data to be published by providing signed written informed consents. 


\section{Competing interests}

The authors declare that they have no competing interests.

\section{References}

1. Ho XN, Wee IJ, Syn N, Harrison M, Wilson L and Choong AM: The endovascular repair of blunt traumatic thoracic aortic injury in Asia: A systematic review and meta-analysis. Vascular 27: 213-223, 2019.

2. Brasel KJ, Moore EE, Albrecht RA, deMoya M, Schreiber M, Karmy-Jones R, Rowell S, Namias N, Cohen M, Shatz DV and Biffl WL: Western trauma association critical decisions in trauma: Management of rib fractures. J Trauma Acute Care Surg 82: 200-203, 2017.

3. Pieracci FM, Majercik S, Ali-Osman F, Ang D, Doben A, Edwards JG, French B, Gasparri M, Marasco S, Minshall C, et al: Consensus statement: Surgical stabilization of rib fractures rib fracture colloquium clinical practice guidelines. Injury 48: 307-321, 2017.

4. Bemelman M, de Kruijf MW, van Baal M and Leenen L: Rib fractures: To fix or not to fix? An evidence-based algorithm. Korean J Thorac Cardiovasc Surg 50: 229-234, 2017.

5. Kocher GJ, Sharafi S, Azenha LF and Schmid RA: Chest wall stabilization in ventilator-dependent traumatic flail chest patients: Who benefits. Eur J Cardiothorac Surg 51: 696-701, 2017.

6. Sun ZY, Wang DB, Xia HG, Zhu DQ, Zhu PZ, Deng LM, Zhang YM and Zhang HQ: Rib surface positioning ruler. Patent CN209733991U and ZL 201920 189426.4. Filed February 11, 2019; Issued December 6, 2019.

7. Xia H, Zhu P, Li J, Zhu D, Sun Z, Deng L, Zhang Y and Wang D: Thoracoscope combined with internal support system of chest wall in open reduction and internal fixation for multiple rib fractures. Exp Ther Med 16: 4650-4654, 2018.

8. Correction: No benefit to surgical fixation of flail chest injuries compared with modern comprehensive management: Results of a retrospective cohort study. Can J Surg 60: 7, 2017.

9. Uchida K, Nishimura T, Takesada H, Morioka T, Hagawa N, Yamamoto T, Kaga S, Terada T, Shinyama N, Yamamoto H and Mizobata Y: Evaluation of efficacy and indications of surgical fixation for multiple rib fractures: A propensity-score matched analysis. Eur J Trauma Emerg Surg 43: 541-547, 2017.
10. Pieracci FM, Lin Y, Rodil M, Synder M, Herbert B, Tran DK, Stoval RT, Johnson JL, Biffl WL, Barnett CC, et al: A prospective, controlled clinical evaluation of surgical stabilization of severe rib fractures. J Trauma Acute Care Surg 80: 187-194, 2016.

11. Wiese MN, Kawel-Boehm N, de la Santa PM, Al-Shahrabani F, Toffel M, Rosenthal R, Schäfer J, Tamm M, Bremerich J and Lardinois D: Retraction to 'Functional results after chest wall stabilization with a new screwless fixation device' (Eur J Cardiothorac Surg 47: 868-875, 2015). Eur J Cardiothorac Surg 53: 695, 2018.

12. Dehghan N: Challenges in plate fixation of chest wall injuries. Injury 49 (Suppl 1): S39-S43, 2018.

13. Klein GT, Lu Y and Wang MY: 3D printing and neurosurgery-ready for prime time. World Neurosurg 80: 233-235, 2013.

14. Nolasco-de la Rosa AL, Mosiñoz-Montes R, Matehuala-García J, Román-Guzmán E, Quero-Sandoval F and Reyes-Miranda AL: Unstable thorax fixation with bioabsorbable plates and screws. Presentation of some cases. Cir Cir 83: 23-28, 2015 (In Spanish).

15. Morodomi Y, Okamoto T, Tagawa T, Shoji F, Katsura M, Fujishita T, Fujiyoshi T, Akahoshi T, Yasuda M and Maehara Y: A novel method of using bioabsorbable materials for the surgical repair of flail chest. J Trauma Acute Care Surg 81: 984-987, 2016

16. Nolasco-de la Rosa AL, Mosiñoz-Montes R, Matehuala-García J, Cuautle-Ramírez AA, Román-Guzmán E, Reyes-Miranda AL and Quero-Sandoval F: Thoracic inestability fixed with bioabsorbable screws and plates. Acta Ortop Mex 30: 311-315, 2016 (In Spanish).

17. Zhuo C, Lei L, Yulin Z, Wentao L, Shuangxia W, Chao W, Yaqian Z, Shuman H and Dong D: Creation and validation of three-dimensional printed models for basic nasal endoscopic training. Int Forum Allergy Rhinol 9: 695-701, 2019.

18. Taylor BC, French BG and Fowler TT: Surgical approaches for rib fracture fixation. J Orthop Trauma 27: e168-e173, 2013.

19. Pishbin E, Ahmadi K, Foogardi M, Salehi M, Seilanian Toosi F and Rahimi-Movaghar V: Comparison of ultrasonography and radiography in diagnosis of rib fractures. Chin J Traumatol 20: 226-228, 2017.

This work is licensed under a Creative Commons Attribution-NonCommercial-NoDerivatives 4.0 International (CC BY-NC-ND 4.0) License. 